\title{
Correction to: Neuroprotective Role of Novel Triazine Derivatives by Activating Wnt/ $\beta$ Catenin Signaling Pathway in Rodent Models of Alzheimer's Disease
}

\author{
Anshuman Sinha ${ }^{1} \cdot$ Riyaj S. Tamboli ${ }^{1} \cdot$ Brashket Seth $^{2,3} \cdot$ Ashish M. Kanhed ${ }^{1} \cdot$ Shashi Kant Tiwari ${ }^{2,3}$. \\ Swati Agarwal ${ }^{2,3} \cdot$ Saumya Nair ${ }^{2} \cdot$ Rajani Giridhar $^{1} \cdot$ Rajnish Kumar Chaturvedi ${ }^{2}$ Mange Ram Yadav ${ }^{1}$
}

Published online: 28 August 2019

(C) Springer Science+Business Media, LLC, part of Springer Nature 2019

Correction to: Mol Neurobiol (2015); 52(1): 638-52

https://doi.org/10.1007/s12035-014-8899-y

The original version of this article unfortunately contained mistakes in figures.

The authors regret that inadvertent errors were observed in Figures 7, 9 and 11. The corrected representative images are now incorporated. This correction in no way changes the text and conclusion of the article.

The authors regret for this error and would like to apologize for any inconvenience caused to the readers.

Publisher's Note Springer Nature remains neutral with regard to jurisdictional claims in published maps and institutional affiliations.

The online version of the original article can be found at https://doi.org/ 10.1007/s12035-014-8899-y

Rajnish Kumar Chaturvedi

rajnish@iitr.res.in

$\triangle$ Mange Ram Yadav

mryadav11@yahoo.co.in

1 Pharmacy Department, Faculty of Technology \& Engineering,

Kalabhavan, The MS University of Baroda,

Vadodara, Gujarat 390001, India

2 Developmental Toxicology Division, Systems Toxicology Group, Council of Scientific and Industrial Research-Indian Institute of Toxicology Research, Lucknow 226001, India

3 Academy of Scientific and Innovative Research (AcSIR), New Delhi 110001, India 


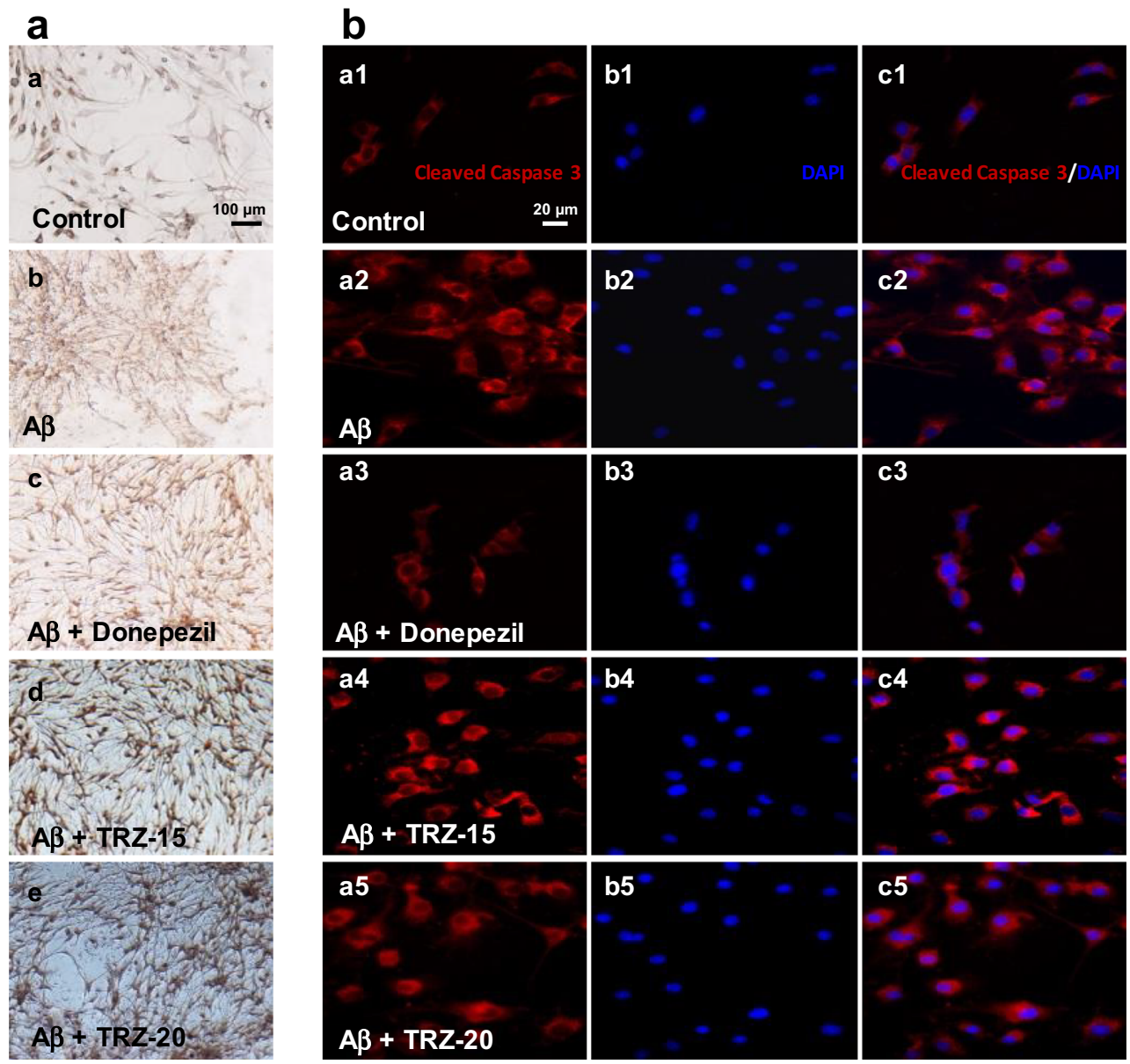

Fig. 7 
a

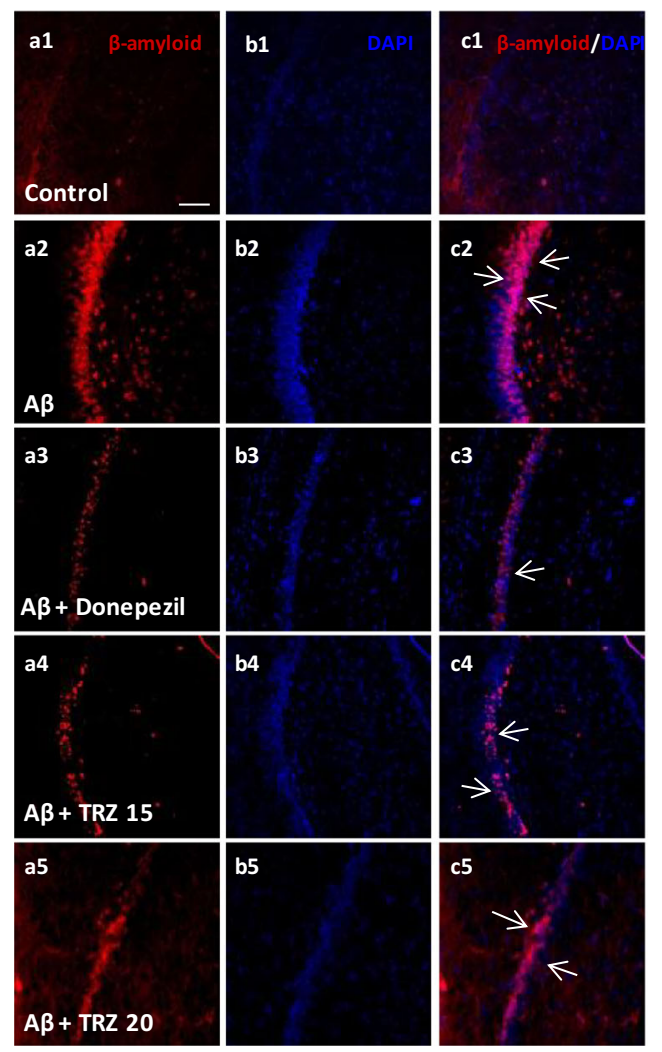

b

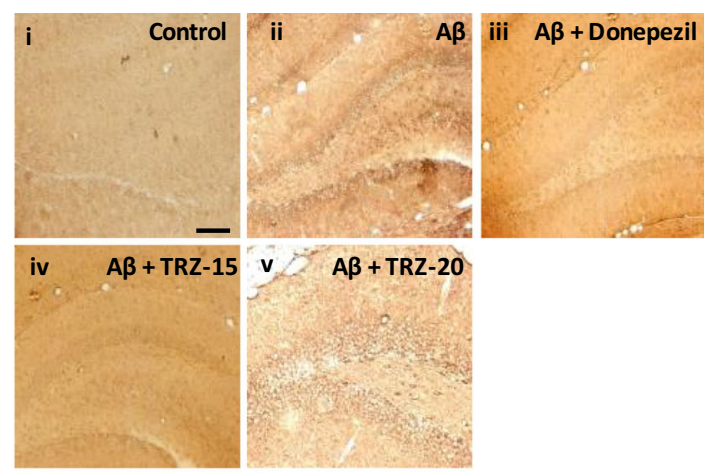

C

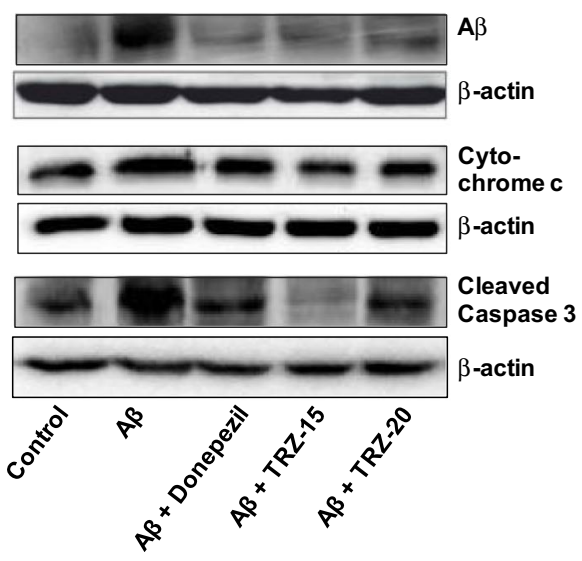

Fig. 9

a

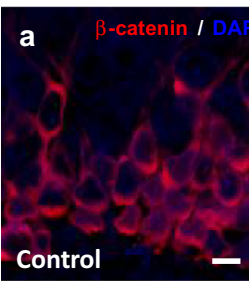

d

d

$\frac{98}{20.25}$

$A \beta+$ TRZ-15

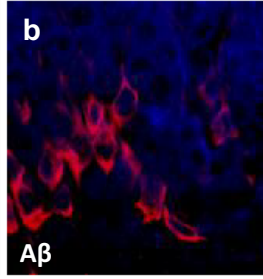

e

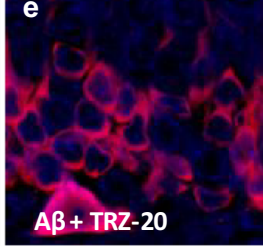

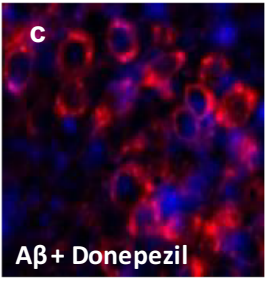

$A \beta+$ Donepezil
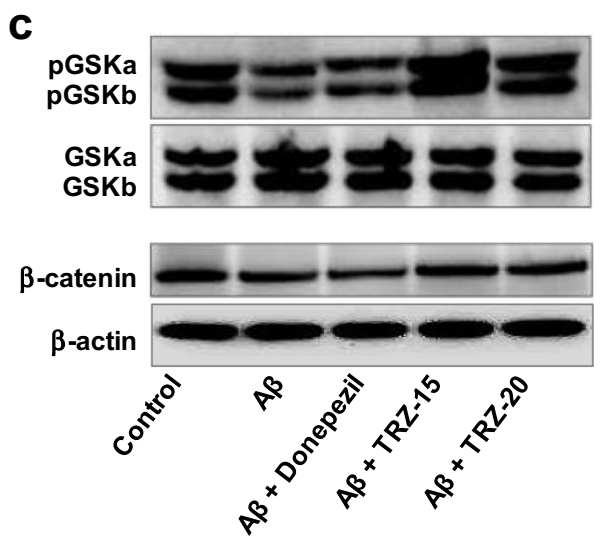

Fig. 11 